\title{
RESEÑA DEL LIBRO: ENVIRONMENTAL LAW ACROSS CULTURES. COMPARISONS FOR LEGAL PRACTICE. EARTHSCAN FROM ROUTLEDGE, JUNKER, KIRK W. (ED.), 2020
}

\author{
Cesar Leonidas Gamboa Balbín \\ Director Ejecutivo de DAR (Derecho Ambiente y Recursos Naturales)
}

La publicación que ha editado el profesor Kirk Junker de la Universidad de Colonia (Alemania), pone en relieve el análisis comparativo del derecho ambiental. En los capítulos I y II, Junker resalta la importancia de la interpretación comparativa en el derecho ambiental. Ciertamente hay muchos retos para llevar a cabo tal empresa, pero es claro que esta es parte de una ventaja evolutiva del aprendizaje del ser humano. Este proceso de interpretación comparativa ha llegado a realizarse no solo sobre el cuerpo legal, sino también sobre las practicas, tradiciones y culturas legales, que pueden transferirse en este mundo globalizado por instituciones internacionales.

Una de las ventajas de la interpretación comparativa puede llegar incluso a evitar la guerra, pues crea oportunidades de integración social y política para seguir desarrollándonos como sociedades, tal como sucede con la Unión Europea. En síntesis, las ventajas son innumerables, pero podríamos decir que la central es que el análisis de modelos legales extranjeros podría mejorar nuestro propio derecho nacional.

En el capítulo II, Junker utiliza el antiguo método Accessus ad autores para presentar la forma de comparar a través de las siguientes preguntas: ¿Por qué comparar? (ya respondido en el cap. I), ¿quiénes comparan? (abogados, autoridades, expertos), ¿qué comparar? (conocimiento jurídico, practicas, políticas, costumbres, textos, 
recepción del derecho), ¿cuándo? (historia del derecho), ¿dónde? (perspectivas globalesylocales),losmediosyel cómo, siendoestoimportantepara evitarunasuerte de justificación de la perspectiva colonial como una situación «natural», «normal», una suerte de estándar dominante en este proceso de comparación. Podemos señalar que Junker concluye que comparar enriquece nuestro análisis, pues no es una interpretación fría de estáticos cuerpos, sistemas y familias legales, sino también tradiciones y culturas legales que están en completo desenvolvimiento social.

En el capítulo III, «Locating environmental law functions among legislative, judicial, and implementation bodies» (43 y ss.), Prityi et al. analizan la función del Estado en el desarrollo de conflictos ambientales a través de tres dicotomías: la primera, entre el derecho público, que prioriza las soluciones de los conflictos legales a través del interés común mediante los cuerpos legales, y el derecho privado, que privilegia el modelo de disputa de los intereses privados en procesos judiciales; la segunda dicotomía se produce entre las familias legales (civil law y common law), pues enmarca soluciones racionales y que provienen de la experiencia práctica en función a la aplicación de las fuentes del derecho, normativas o por la costumbre; y la tercera dicotomía esta en cómo los sistemas políticos presidencialista y parlamentario afectan la regulación ambiental, donde el primero prioriza la creación de los organismos especializados ejecutivos para tratar la gestión ambiental y sus problemas (derecho administrativo ambiental).

Los elementos resaltantes para el debate de los conflictos ambientales en el Perú se encuentran en la aplicación de «Public Trust Doctrine» y la teoría eminente de los recursos naturales, especialmente su utilidad para la mejora del planeamiento de los recursos naturales o en los sistemas de evaluación del impacto ambiental. Nuestros retos van por mejorar el sistema de planeamiento y seguir fortaleciendo el sistema de evaluación ambiental.

Con respecto al sistema privado de obligaciones ambientales, probablemente es la mayor diferencia con respecto a otros sistemas legales. En Perú no es eficiente ni inspira confianza que las cortes solucionen conflictos ambientales porque los procesos judiciales son costosos y toman mucho tiempo. Es cierto que se han producido colaboraciones desde la sociedad civil mediante Amicus Curiae, y en las vías administrativas a través del «tercero interesado en el procedimiento administrativo sancionador ambiental»; y en la región se conocen casos como el de Chevron contra Ecuador, o incluso algunos arreglos judiciales (Oxidental vs Achuar en Estados Unidos) y extrajudiciales utilizados por organizaciones indígenas. No obstante, estos casos son los pocos.

Un segundo tema resaltante es que muchos sistemas legales han fortalecido y creado instituciones especializadas en materia ambiental, lo que en América Latina es una preocupación fuerte por el que los arreglos institucionales ayuden a implementar los cuerpos legales ambientales. Los países de la región presentan una vieja omnipresencia estatal y una extensa burocracia, sin embargo, en el tema ambiental este fortalecimiento institucional solo es de los últimos treinta años.

La última institución comparativa que resaltan los autores son los permisos y licencias ambientales, no solo porque engarzan dentro de la gobernanza de los recursos naturales, es decir, instrumentos de planeamiento 
(ordenamiento territorial), permisos de uso de recursos naturales (contratos, licencias) y la certificación ambiental. Comparativamente, podemos encontrar que la participación y transparencia son muy limitadas en el proceso de toma de decisiones, y que el impacto de los permisos puede, a su vez, tener impactos en el ordenamiento e incluso en la afectación de otros derechos en el territorio.

En el caso de la situación de la legislación china, es fundamental analizar el derecho ambiental en China desde adentro y desde afuera. Como dicen los autores, es importante reconocer los avances, como el ascenso de la regulación ambiental china, el desarrollo en China del concepto de «civilización ecológica» y su inclinación por evitar conflictos ambientales. Sin embargo, el reto de la legislación ambiental china es la aplicación del principio de extraterritorialidad en materia ambiental; es decir, cómo China regula las obligaciones ambientales públicas y privadas en sus inversiones en el extranjero.

Finalmente, ha sido muy placentero encontrar el uso de pasajes de Octavio Paz para explicar la interpretación ambiental como una forma de tender puentes entre la literatura y el derecho, una evidencia de que los autores han querido mostrar la necesidad de comparar «lo ambiental» desde la multidisciplinariedad.

(14 de octubre de 2020) 